\title{
Role of MRI \& US in the Evaluation of Knee Joint Affection in Patients with Juvenile Idiopathic Arthritis
}

\author{
AYA M.B.F. HASHEM, M.D.; BASMA M.A. ALKALAAWY, M.D. and NOUR M.M. KANDIL, M.D. \\ The Department of Radiology, Faculty of Medicine, Cairo University, Egypt
}

\begin{abstract}
Background: Juvenile Idiopathic Arthritis (JIA) is defined as arthritis of unknown etiology beginning before the age of 16 years and persisting for at least 6 weeks, while excluding other known conditions.
\end{abstract}

Aim of Study: The purpose of this study is to highlight the beneficial role of MRI \& US in the evaluation of knee joint affection in patients with juvenile idiopathic arthritis, especially in early cases.

Patients and Methods: The study was carried out on fourty patients (26 females and 14 males), referred to the Radiology Department of Kasr El-Ainy Hospital from Abo El-Rish Pediatric Hospital. Their age ranged from 2.5 years up to 13 years. All patients underwent examination of the more symptomatic knee joint using MRI with intravenous contrast (Gadolinium) and Ultrasound (US) examinations. The results of the ultrasound were compared to those of MRI, with the MRI being the gold standard of diagnosis.

Results: Among the studied cases ultrasound was able to detect joint effusion in all cases as a compressible anechoic area. It was able to detect synovitis as synovial thickening and increased vascularity on power Doppler in all cases which is evident mainly in the suprapatellar recess. The accuracy of US regarding both effusion and synovitis was $100 \%$. Ultrasound had great potential to identify the normal cartilage and allows for differentiation of the abnormal morphology such as loss of clarity, irregularity, and defects on the surface. In our study ultrasound was able to demonstrate most of the cases. The overall accuracy regarding cartilage changes was $90 \%$. In this study six of the cases had bone erosions which were detected on MRI. US was able to detect four of these cases. The overall accuracy of US regarding erosions was $95 \%$.

Conclusion: Ultrasound has the ability to demonstrate knee joint pathology in early JIA which can help start early treatment or modify already existing one to prevent permanent joint damage. At this point in time, however, it is not possible to determine that ultrasound is superior to MRI, especially regarding bone erosions and the fact that it is operator dependent and needs experience.

Correspondence to: Dr. Aya M.B.F. Hashem, The Department of Radiology, Faculty of Medicine, Cairo University, Egypt
Key Words: Juvenile Idiopathic Arthritis - Ultrasound - MRI - Knee joint.

\section{Introduction}

ACCORDING to ILAR (International League of Associations for Rheumatology) Juvenile Idiopathic Arthritis (JIA) was introduced to replace the two other terms: Juvenile Rheumatoid Arthritis (JRA) and Juvenile Chronic Arthritis (JCA). Juvenile Idiopathic Arthritis (JIA) is the most common cause of chronic joint inflammation in childhood. It is defined as arthritis of unknown cause lasting over 6 -week duration in a child less than 16 years of age $[\mathbf{1 , 2}]$.

In juvenile idiopathic arthritis, the knee joint is the most commonly affected joint (frequently monoarticular onset). Early detection and treatment of the disease activity and to identify children who are at risk for joint destruction and poor functional outcome are the general aims to improve long term outcome $[\mathbf{1 , 3 , 4}]$.

Conventional radiography has played an important role in the management of JIA, but the trend is towards early suppression of inflammation to prevent irreversible damage of cartilage and bone has shifted the emphasis from detecting damage (using radiography) to detecting early joint changes of JIA [5] .

The earliest MRI abnormality to appear in JIA is synoivitis. The other MR findings include erosion, bone marrow edema, effusion \& cartilage destruction [6].

US has been used to directly visualize and objectively quantify synovial inflammation. More than gray-scale sonography alone, power Doppler may be more representative of true synovitis, 
because the presence of power Doppler signal signifies increased synovial vascularity, associated with active joint. Specifically, the use of dynamic, Doppler, and/or multifocal US assessments can help confirm sites of disease, monitor therapy response, and guide interventions [2,7].

The aim of this study was to demonstrate the role of MRI \& US in the evaluation of knee joint affection in patients with juvenile idiopathic arthritis, especially in early cases.

\section{Patients and Methods}

\section{Patients:}

The current study had been approved by Kasr El-Aini Hospital, Research and Ethical Committee, Cairo University.

This study was carried out on fourty patients (26 females and 14 males), referred to the Radiology Department of Kasr El-Aini Hospital from Abo El-Rish Pediatric Hospital. Their age ranged from 2.5 years up to 13 years. The patients had been evaluated in the current prospective study over the period from May 2018 till August 2019.

\section{Inclusion criteria:}

Pediatric patients with early confirmed clinical and laboratory diagnosis of JIA of the knee joint, age younger than 16 years.

\section{Exclusion criteria:}

1- Patients with other causes of arthritis e.g. systemic lupus patients, and patients with mixed connective tissue diseases.

2- Patients with advanced JIA causing knee joint deformities.

3- Patients with contraindications to MRI study e.g. pacemakers, allergy to contrast material, contraindications to sedation.

\section{Methods:}

All the cases underwent examination of the more symptomatic knee joint using MRI with intravenous contrast (Gadolinium) and Ultrasound examinations.

The main pathological findings were synovitis, effusion, cartilage alterations and bony changes (mainly erosions). The results of the ultrasound were compared to those of MRI, with the MRI being the gold standard of diagnosis.

\section{Protocol of MRI technique:}

MR studies were performed on a 1.5-T MR imaging unit (Intera, Philips medical system). The patients were positioned supine with the affected knee completely or nearly completely extended in the knee coil. Very young patients were sedated to abolish motion artifacts.

\section{MRI imaging sequences:}

The MRI study included the following pulse sequences (Table 1):

T1 (sagittal plane), T2 (sagittal plane), T1 SPIR pre contrast (sagittal and coronal planes) T 1 SPIR post contrast (sagittal and coronal planes) and 3D WATSc (coronal plane).

Table (1): Shows the MRI pulse sequences used in our study.

\begin{tabular}{|c|c|c|c|c|c|}
\hline Parameters & $\begin{array}{c}\text { Sagittal } \\
\mathrm{T} 1\end{array}$ & $\begin{array}{c}\text { Sagittal } \\
\text { T2 }\end{array}$ & $\begin{array}{l}\text { Sagittal } \\
\text { T1 SPIR }\end{array}$ & $\begin{array}{l}\text { Coronal } \\
\text { T1 SPIR }\end{array}$ & WATSc \\
\hline TR & 600 & 4230 & 500 & 500 & 20 \\
\hline TE & 17 & 100 & 20 & 20 & 8 \\
\hline $\begin{array}{l}\text { FO V: } \\
\text { - Anterior/posterior } \\
\text { - Right/left } \\
\text { - Feet/head }\end{array}$ & $\begin{array}{l}30 \\
35 \\
50\end{array}$ & $\begin{array}{l}30 \\
35 \\
50\end{array}$ & $\begin{array}{l}30 \\
50 \\
20\end{array}$ & $\begin{array}{l}30 \\
50 \\
20\end{array}$ & $\begin{array}{l}20 \\
60 \\
40\end{array}$ \\
\hline Slice thickness & $4 \mathrm{~mm}$ & $4 \mathrm{~mm}$ & $4 \mathrm{~mm}$ & $4 \mathrm{~mm}$ & $4 \mathrm{~mm}$ \\
\hline Slice gap & $1 \mathrm{~mm}$ & $1 \mathrm{~mm}$ & $1 \mathrm{~mm}$ & $1 \mathrm{~mm}$ & $1 \mathrm{~mm}$ \\
\hline
\end{tabular}

\section{Protocol of Ultrasound technique:}

Grey scale ultrasound was performed directly after MRI examination using Philips HDI 5000 SonoCT machine with a 7.5MHZ linear transducer. It was combined with color Doppler to detect vascularity and was performed on both knees. The normal or less symptomatic knee was used as a normal reference to the more symptomatic knee. Routine examination of the joint was performed including the anterior, medial, lateral, and posterior compartments, focusing mainly on the suprapatellar bursa which appeared to be the most evident site for synovial changes.

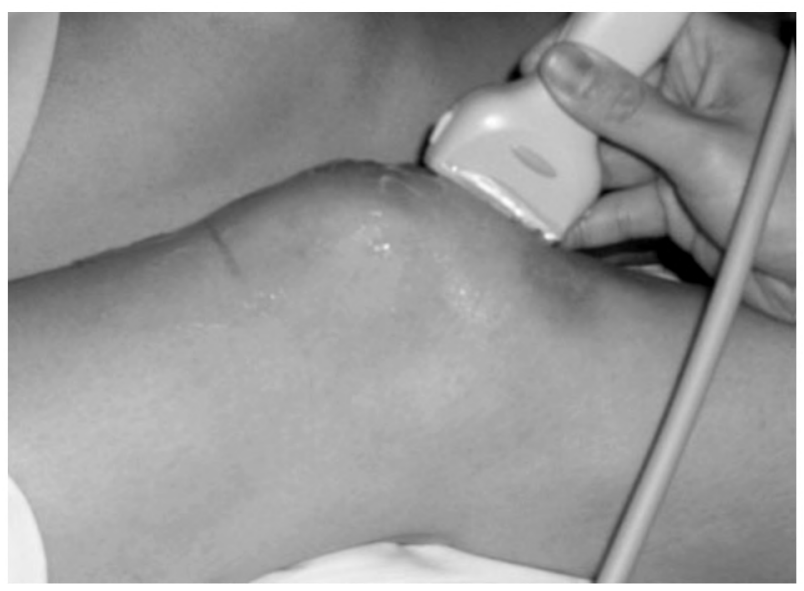

Fig. (1): Patient position for US examination. The knees are flexed to 30 degrees with a pillow underneath them [8] 
A- Anterior examination: Patient lies supine on bed with knee flexed 20-30 degrees Fig. (1). Alternatively patient may sit on the side of a raised bed with foot resting on Sonographer's knee for

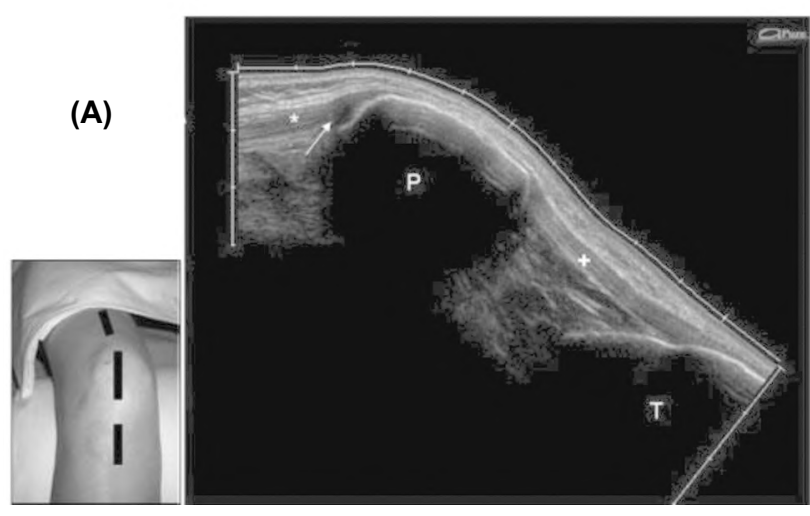

support. Identify the normal anatomy, including: The patella, suprapatellar recess, patellar ligament and it's insertion, quadriceps tendon, cartilage structure are assessed Figs. (2-6).

Fig. (2): Longitudinal sections. The quadriceps tendon is a hyperechoic, fibrillar structure (collagen fibres) that lies between the subcutaneous fat and the suprapatellar fat. At its insertion the tendon appears hypoechoic due to anisotropy ( $\rightarrow$ ) in Fig. (A) *quadriceps tendon, +patellar tendon, P patella, T tibia. The probe is orientated in the sagittal plane and traced along the course of the extensor tendon system [9]

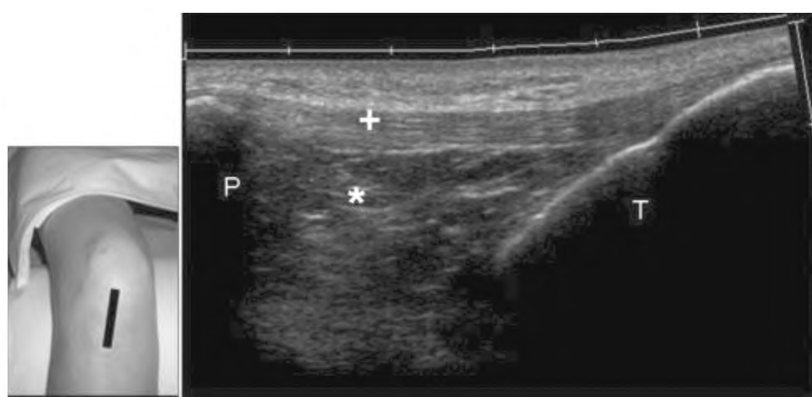

Fig. (3): Longitudinal section with the probe orientated between the inferior pole of the patella and the tibial tuberosity. The patellar tendon $(+)$ runs from the inferior pole of the patella to the tibial tuberosity between the subcutaneous fat and Hoffa's fat pad (*). P patella, T tibia. Hoffa's fat pad consists of lobules of hypoechoic fat separated by hyperechoic fibrous septae [9]

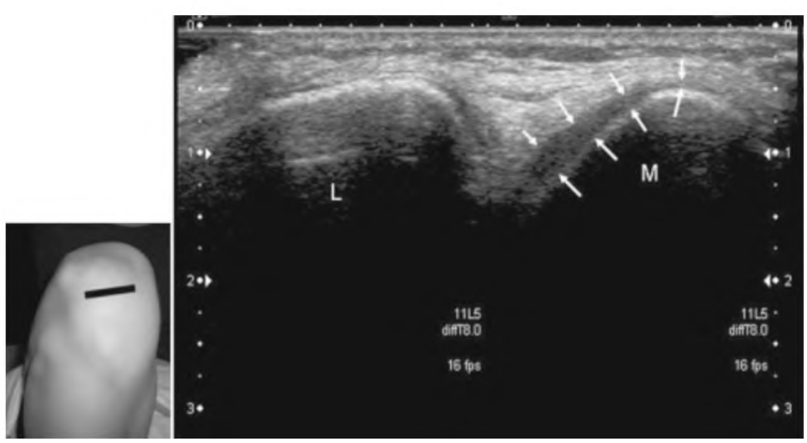

Fig. (5): Transverse view of the femoral cartilage: $M$ medial condyle, $\mathrm{L}$ lateral condyle. The cartilage is a smooth anechoic line, covering the hyperechoic bone, which tapers smoothly at the joint margins $\rightarrow$ [9]

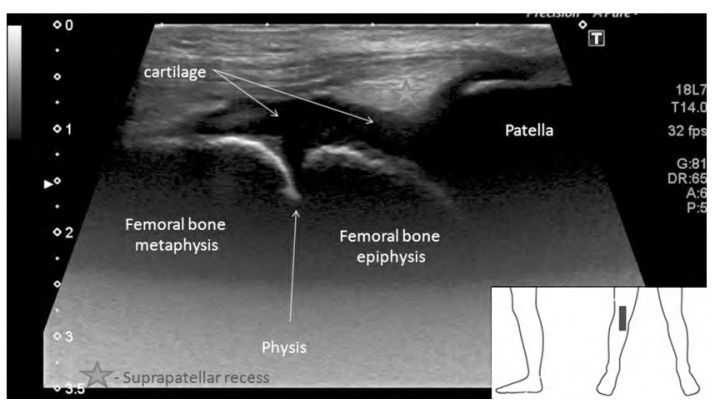

Fig. (4): Longitudial view. Suprapatellar recess. Normal ultrasound anatomy in 7-year-old child (Department of Radiology. Wroclaw University Hospital).

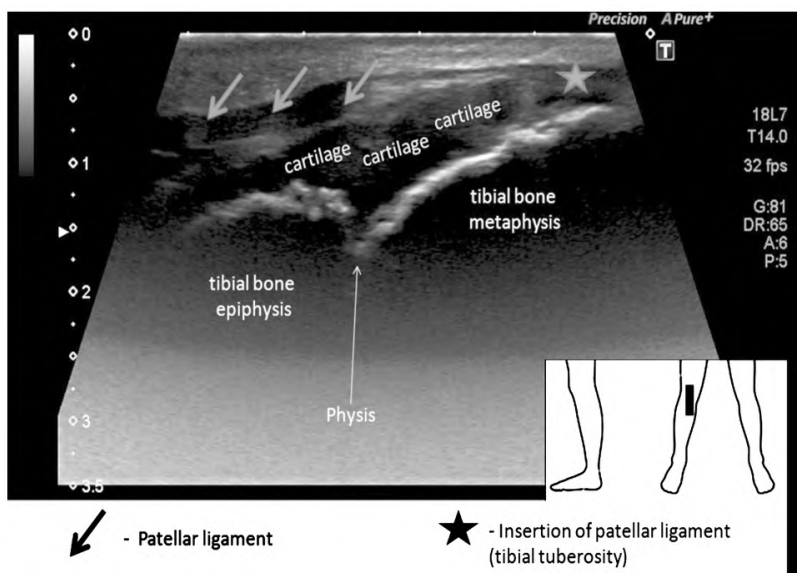

Fig. (6): Longitudinal view. Patellar ligament. Normal ultrasound anatomy in 7-year-old child (Department of Radiology. Wroclaw University Hospital). 
B- Medial \& lateral examination: May be scanned as above. Assess the medial and lateral collateral ligaments, meniscal margins, ossification centers \& cartilage Figs. $(7,8)$.

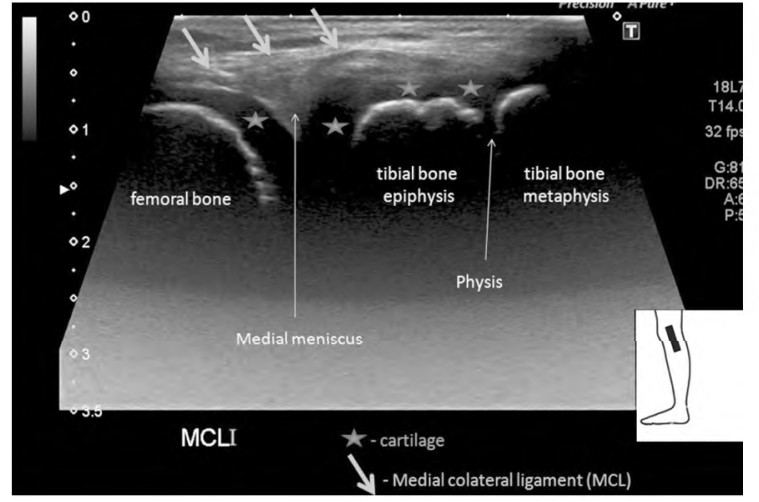

Fig. (7): Longitudial view. Medial aspect of knee joint. Normal ultrasound anatomy in 7-year-old child (Department of Radiology. Wroclaw University Hospital).

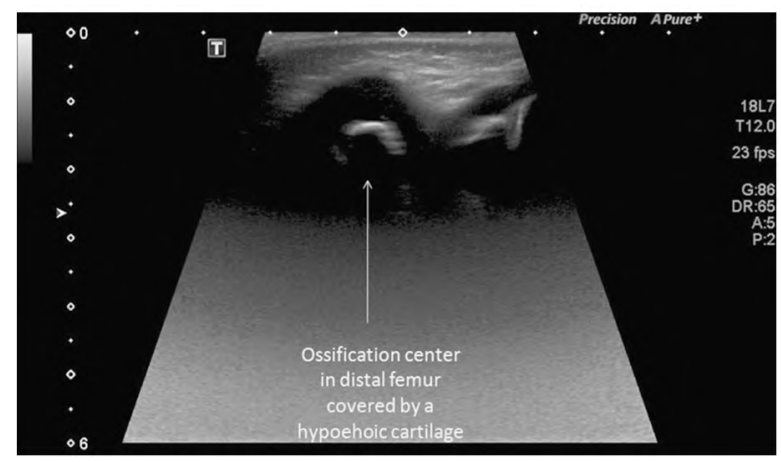

Fig. (8): 5-month-old child. Longitudinal view of anterior knee compartment. Note the ossification center in distal femur and hypoechoic cartilage (Department of Radiology. Wroclaw University Hospital).

C- Posterior examination: Patient prone on bed, knee flexed slightly with a pad under the ankle for support. Survey the entire fossa to identify the normal anatomy, including; popliteal fossa \& vessels Figs. $(9,10)$.

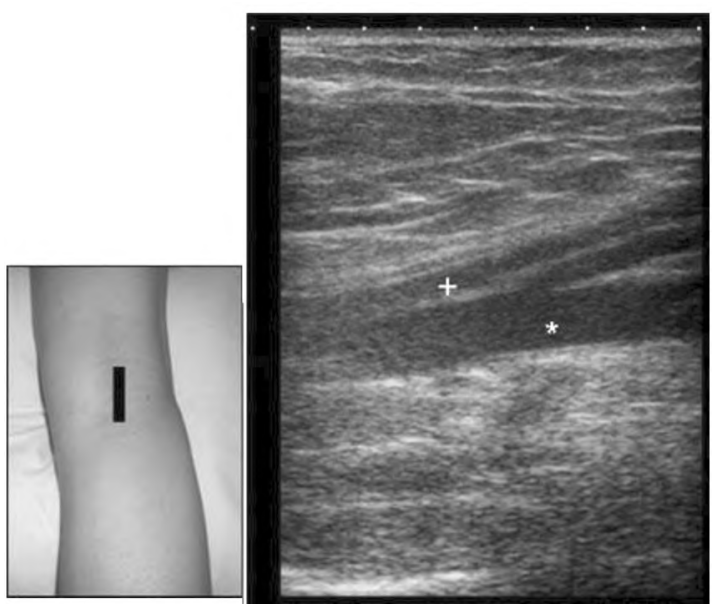

Fig. (9): The popliteal vessels in LS. The vein (+) lies superficial to the artery $(*)$. The artery can be seen to bifurcate [10].

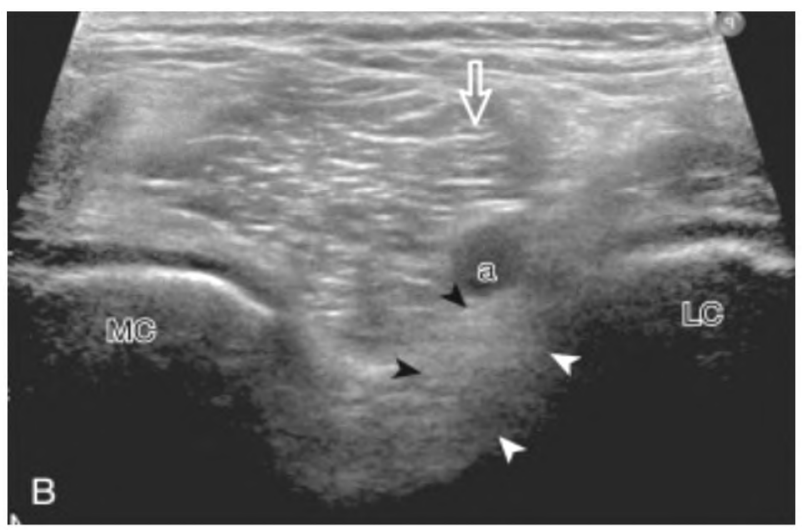

Fig. (10): Posterior knee evaluation. Transverse imaging over the posterior distal femur shows: Medial (MC) and lateral (LC) femoral condyles, popliteal artery (a), tibial nerve (open arrow), and anterior cruciate ligament (arrowheads) in the lateral aspect of the intercondylar notch (radiology key, knee ultrasound).

\section{Results}

40 patients suffering from juvenile rheumatoid arthritis of the knee joint were included in this study. Patients' ages ranged from 2.5 to 13 years with a mean age 8.9 years.

Out of the 40 cases, US was able to detect 38 positive cases of knee joint effusion, all cases showed knee joint synovitis, 12 positive cases of knee joint cartilaginous changes, 4 positive cases of knee joint bone erosions \& no positive cases of bone marrow edema were detected.

Table (2) shows the number of cases and percentage of the different findings detected by US in the studied patients.

Table (2): The number of cases and percentage of knee joint effusion, synovitis, cartilage changes, bone erosions $\&$ bone marrow edema by US in the studied patients.

\begin{tabular}{|c|c|c|c|}
\hline US & Positive & Negative & Total \\
\hline \multicolumn{4}{|l|}{ Effusion: } \\
\hline Number of cases & 38 & 2 & 40 \\
\hline Percent $(\%)$ & 95 & 5 & 100 \\
\hline \multicolumn{4}{|l|}{ Synovitis: } \\
\hline Number of cases & 40 & 0 & 40 \\
\hline Percent $(\%)$ & 100 & 0 & 100 \\
\hline \multicolumn{4}{|l|}{ Cartilage changes: } \\
\hline Number of cases & 12 & 28 & 40 \\
\hline Percent $(\%)$ & 30 & 70 & 100 \\
\hline \multicolumn{4}{|l|}{ Bone erosions: } \\
\hline Number of cases & 4 & 36 & 40 \\
\hline Percent $(\%)$ & 10 & 90 & 100 \\
\hline \multicolumn{4}{|l|}{ Bone marrow edema: } \\
\hline Number of cases & 0 & 40 & 40 \\
\hline Percent $(\%)$ & 0 & 100 & 100 \\
\hline
\end{tabular}


Out of the 40 cases, MRI was able to detect 38 positive cases of knee joint effusion, all cases showed knee joint synovitis, 16 positive cases of knee joint cartilaginous changes, 6 positive cases of knee joint bone erosions \& no positive cases for bone marrow edema were detected.

Table (3) shows the number of cases and percentage of the different findings detected by MRI in the studied patients.

Table (3): The number of cases and percentage of knee joint effusion, synovitis, cartilage changes, bone erosions $\&$ bone marrow edema by MRI in the studied patients.

\begin{tabular}{llll}
\hline MRI & Positive & Negative & Total \\
\hline Effusion: & & & \\
$\quad$ Number of cases & 38 & 2 & 40 \\
$\quad$ Percent (\%) & 95 & 5 & 100 \\
Synovitis: & & & \\
$\quad$ Number of cases & 40 & 0 & 40 \\
$\quad$ Percent (\%) & 100 & 0 & 100 \\
Cartilage changes: & & & \\
$\quad$ Number of cases & 16 & 24 & 40 \\
$\quad$ Percent (\%) & 40 & 60 & 100 \\
Bone erosions: & & & \\
$\quad$ Number of cases & 6 & 34 & 400 \\
$\quad$ Percent (\%) & 15 & 85 & 40 \\
Bone marrow edema: & & & 100 \\
$\quad$ Number of cases & 0 & 100 & \\
$\quad$ Percent (\%) & 0 & & \\
\hline
\end{tabular}

Table (4): US effusion versus MRI effusion; the number and percentage of positive and negative cases of knee joint effusion, detected by both US and MRI.

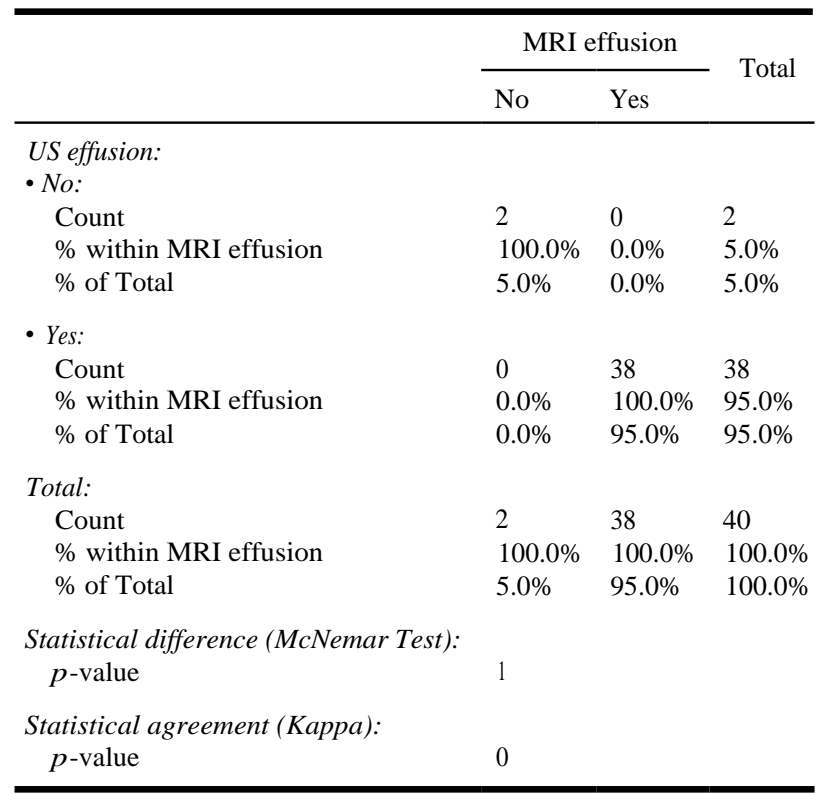

Table (4) shows that as regarding effusion; out of the 40 cases, 38 positive cases and 2 negative cases were detected by both US and MRI as well. The $p$-value of the statistical difference is 1 , which is statistically insignificant and that of agreement is 0 which is significant.

Fig. (11): A male patient 2.5 years old with first time diagnosis of polyarticular JIA. Both knee joints showed signs of inflammation as swelling, pain and redness, however the left knee joint was more affected. Sagittal T1 (A) \& T2 WI (B) of the left knee joint showing effusion which appears as high signal intensity on T2 surrounded by thickened synovium. Grey scale ultrasound of the left knee joint showing the effusion (C) \& increased synovial thickening in the suprapatellar bursa (D).
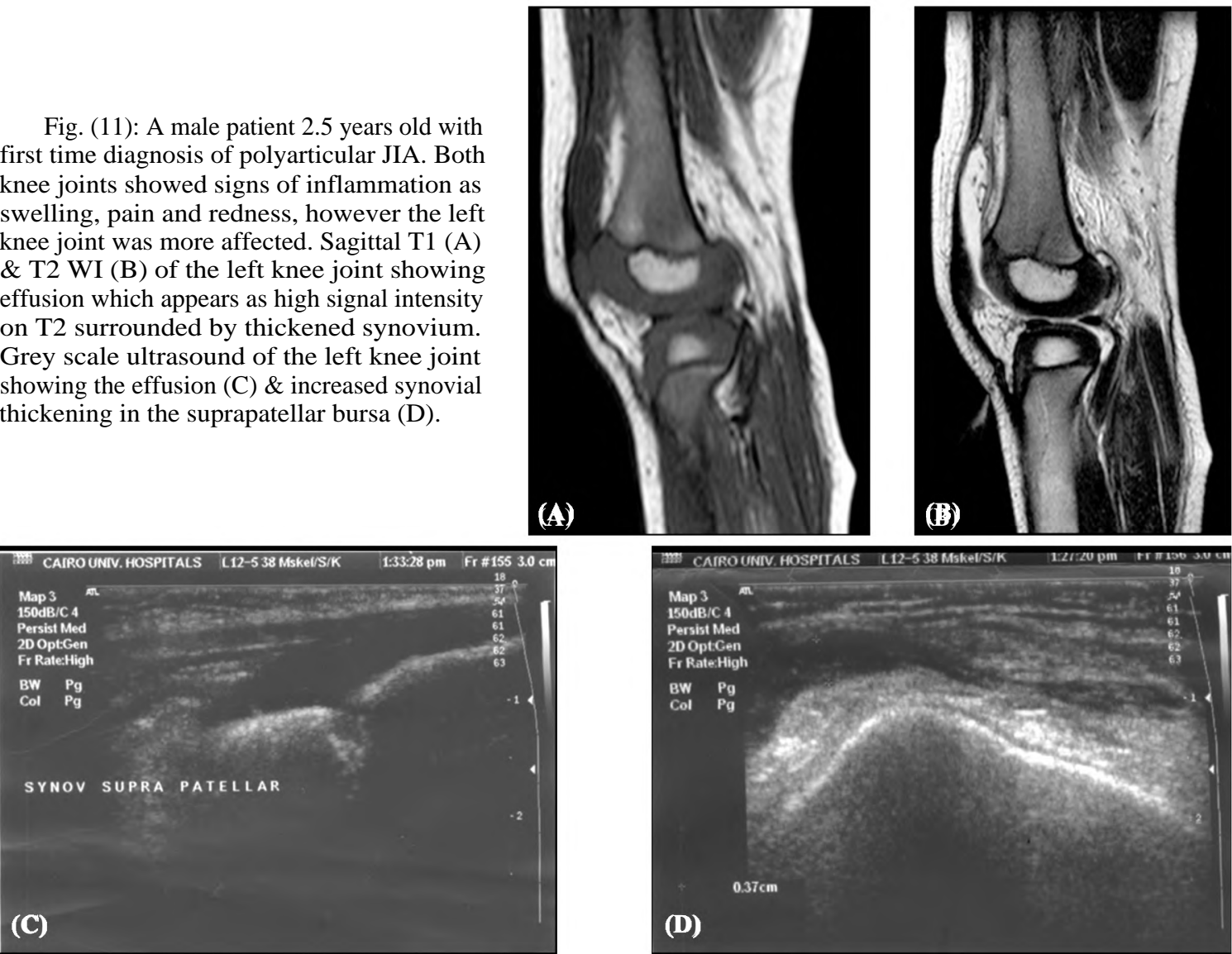

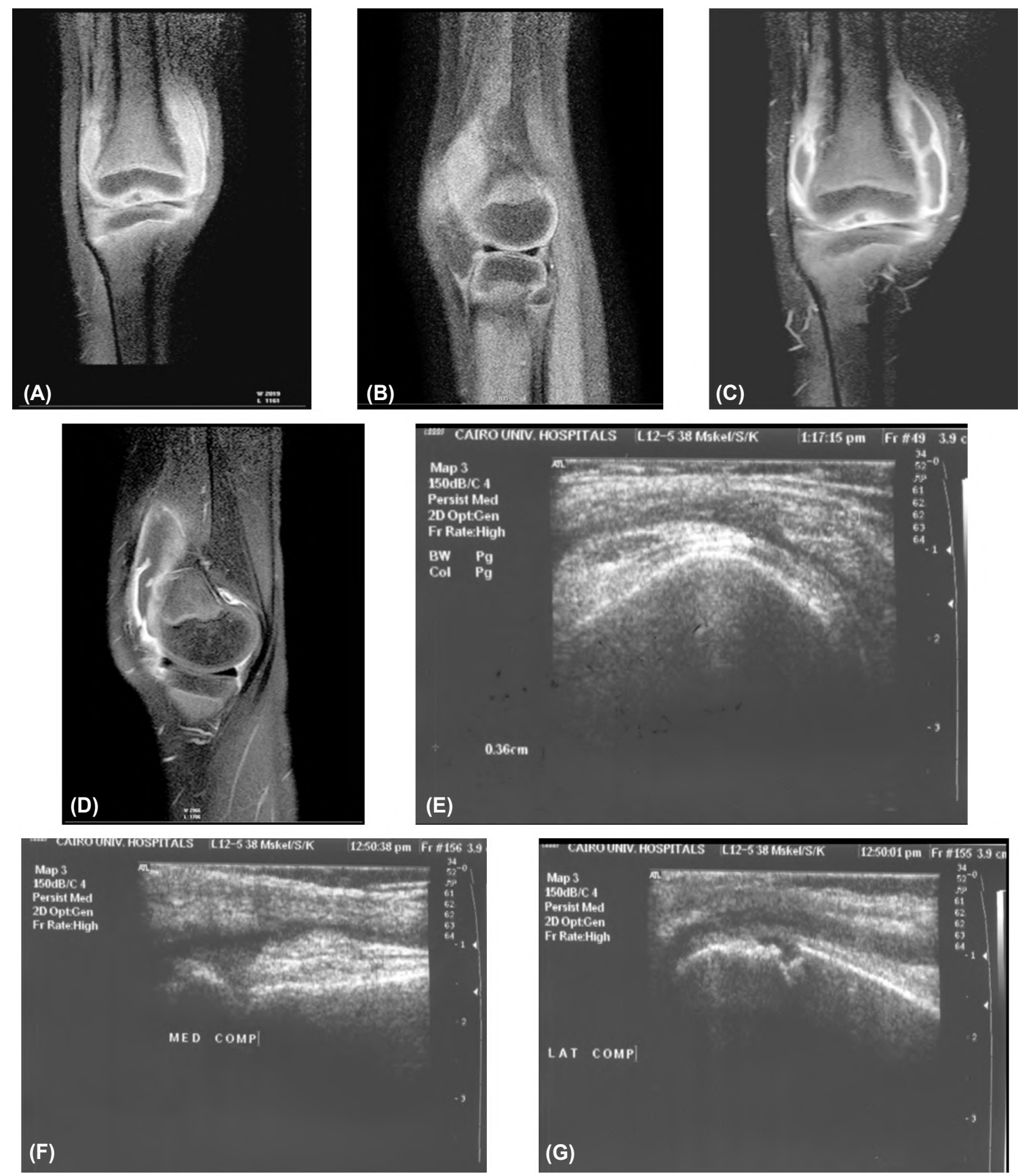

Fig. (12): A female patient 11 years old, with established diagnosis of polyarticular JIA. She was admitted to Abo El-Rish Hospital during an acute attack of the disease. The right knee joint was swollen, painful, red and hot. Sagittal and Coronal TI SPIR pre contrast (A \& B) \& Sagittal and Coronal TI SPIR images post contrast adminstration (C \& D): They show synovial thickening and enhancement. Grey scale ultrasound images (E, F \& G) Showing increased synovial thickening in the suprapatellar bursa as well as the medial and lateral compartments.

Fig. (11) shows a case of left knee joint effusion detected by both US and MRI.

Out of the 40 cases, only positive cases of synovitis were detected by both MRI and US (Table $5)$.

Fig. (12) shows a case of right knee joint synovitis detected by both US and MRI.
Table (5): US synovitis versus MRI synovitis; the number and percentage of positive and negative cases of knee joint synovitis, detected by both US and MRI.

\begin{tabular}{|c|c|c|c|}
\hline \multicolumn{2}{|c|}{ US synovitis } & \multirow{2}{*}{$\begin{array}{c}\text { MRI synovitis (Yes) } \\
40 \\
100.0 \% \\
100.0 \%\end{array}$} & \multirow{2}{*}{$\begin{array}{l}\text { Total } \\
40 \\
100.0 \% \\
100.0 \%\end{array}$} \\
\hline Yes: & $\begin{array}{l}\text { Count } \\
\% \text { within MRI synovitis } \\
\% \text { of Total }\end{array}$ & & \\
\hline Total: & $\begin{array}{l}\text { Count } \\
\% \text { within MRI synovitis } \\
\% \text { of Total }\end{array}$ & $\begin{array}{l}40 \\
100.0 \% \\
100.0 \%\end{array}$ & $\begin{array}{l}40 \\
100.0 \% \\
100.0 \%\end{array}$ \\
\hline
\end{tabular}


Table (6): US cartilage changes versus MRI cartilage changes; the number and percentage of positive and negative cases of knee joint cartilaginous changes, detected by both US and MRI.

\begin{tabular}{|c|c|c|c|}
\hline & \multicolumn{2}{|c|}{$\begin{array}{l}\text { MRI cartilage } \\
\text { changes }\end{array}$} & \multirow[t]{2}{*}{ Total } \\
\hline & No & Yes & \\
\hline \multicolumn{4}{|l|}{$\begin{array}{l}\text { US cartilage changes: } \\
\text { - No: }\end{array}$} \\
\hline Count & 24 & 4 & 28 \\
\hline$\%$ within MRI cartilage changes & $100.0 \%$ & $25.0 \%$ & $70.0 \%$ \\
\hline$\%$ of Total & $60.0 \%$ & $10.0 \%$ & $70.0 \%$ \\
\hline \multicolumn{4}{|l|}{ - Yes: } \\
\hline Count & 0 & 12 & 12 \\
\hline$\%$ within MRI cartilage changes & $0.0 \%$ & $75.0 \%$ & $30.0 \%$ \\
\hline$\%$ of Total & $0.0 \%$ & $30.0 \%$ & $30.0 \%$ \\
\hline \multicolumn{4}{|l|}{ Total: } \\
\hline Count & 24 & 16 & 40 \\
\hline$\%$ within MRI cartilage changes & $100.0 \%$ & $100.0 \%$ & $100.0 \%$ \\
\hline$\%$ of Total & $60.0 \%$ & $40.0 \%$ & $100.0 \%$ \\
\hline $\begin{array}{l}\text { Statistical difference (McNemar Test): } \\
\quad p \text {-value }\end{array}$ & 0.5 & & \\
\hline $\begin{array}{l}\text { Statistical agreement (Kappa): } \\
\quad p \text {-value }\end{array}$ & 0 & & \\
\hline
\end{tabular}

Table (6) shows that as regarding changes; out of the 40 cases, 16 positive cases and 24 negative cases were detected by MRI. Using US only 12 positive and 28 negative cases were detected. The $p$-value of the statistical difference is 0.5 , which is statistically insignificant and that of agreement is 0 which is significant.

Table (7): US bone erosions versus MRI bone erosions; the number and percentage of positive and negative cases of knee joint bone erosions, detected by both US and MRI.

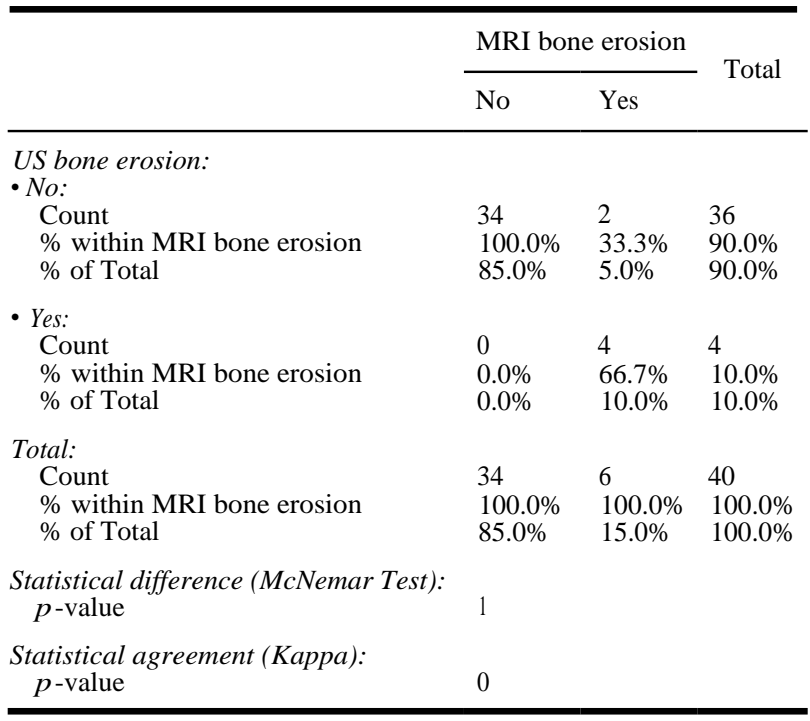

As regarding bone erosions; out of the 40 cases, 6 positive cases and 34 negative cases were detected by MRI. Using US only 4 positive and 36 negative cases were detected. The $p$-value of the statistical difference is 1 , which is statistically insignificant and that of agreement is 0 which is significant (Table 7).

Fig. (13) shows a case of right knee joint effusion, synoivitis \& bone erosions detected by both US and MRI.

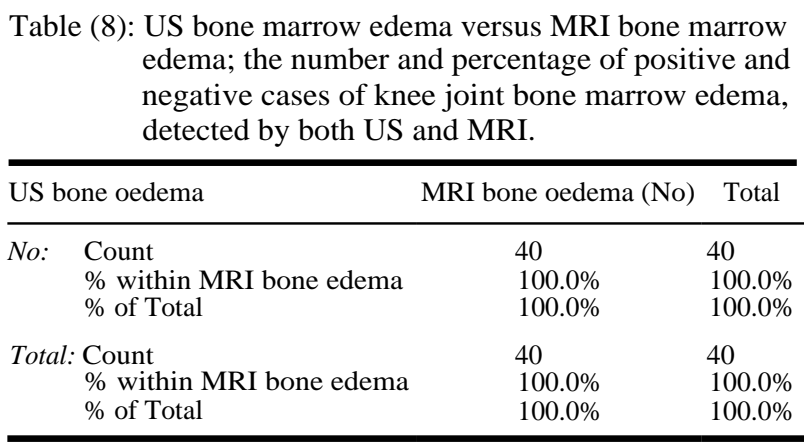

No positive cases of bone marrow edema were detected neither by MRI nor by US.

As regarding effusion, only true positive and true negative cases were detected by US, which means that sensitivity, specificity, positive predictive value and negative predictive value all equal $100 \%$. This makes the overall accuracy of US regarding effusion $100 \%$.

As regarding the synovitis, only true positive cases were detected by US, which means that sensitivity and positive predictive value equal $100 \%$. This makes the overall accuracy of US regarding synovitis equal $100 \%$.

As regarding cartilage changes, 12 positive cases were detected by US as compared to 16 cases detected by MRI. Also, 28 negative cases were detected by US compared to only 24 detected by MRI. This means that 4 false negative cases were detected by US, making the sensitivity $75 \%$ and negative predictive value $85.71 \%$. However, no false positive cases were detected making the specificity and positive predictive value $100 \%$. This is why the overall accuracy of US regarding cartilage changes is $90 \%$.

As regarding bone erosions, 4 positive cases were detected by US as compared to 6 cases detected by MRI. Also, 36 negative cases were detected by US compared to 34 negative cases detected by MRI. This means that only 2 false negative cases were detected by US, making the sensitivity $66.67 \%$ and the negative predictive vale $94.44 \%$. However, no false positive cases were detected making the specificity and positive predictive value $100 \%$. This is why the overall accuracy of US regarding bone erosions is $95 \%$. 

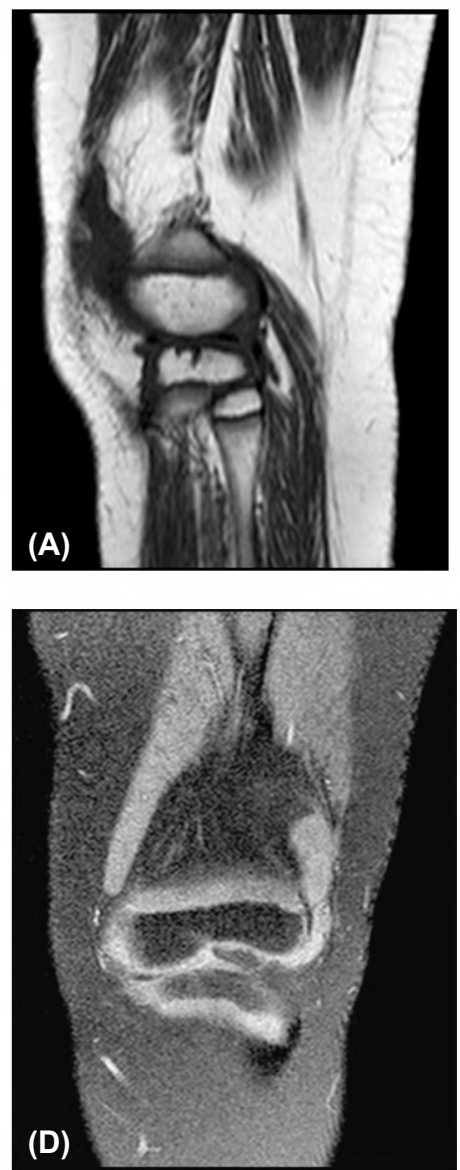
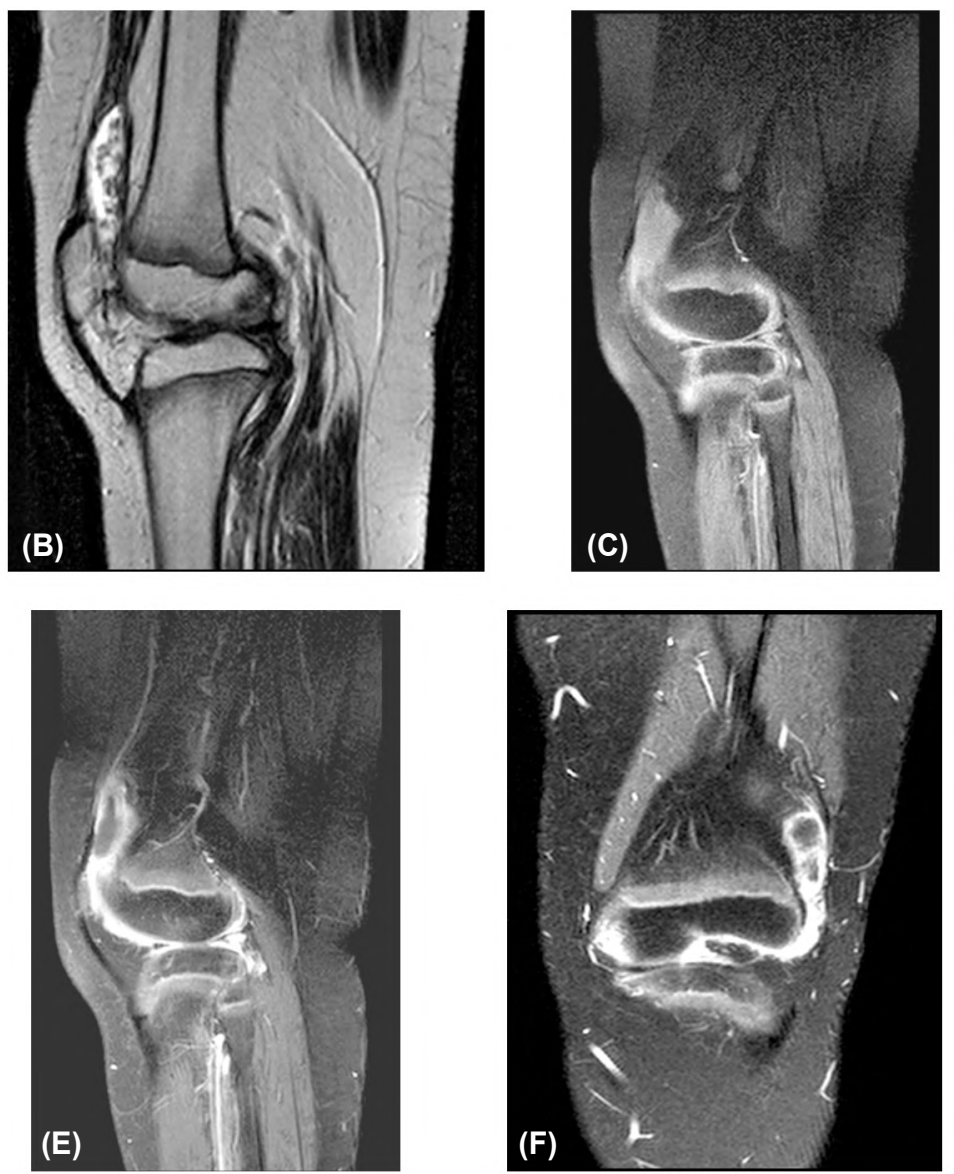
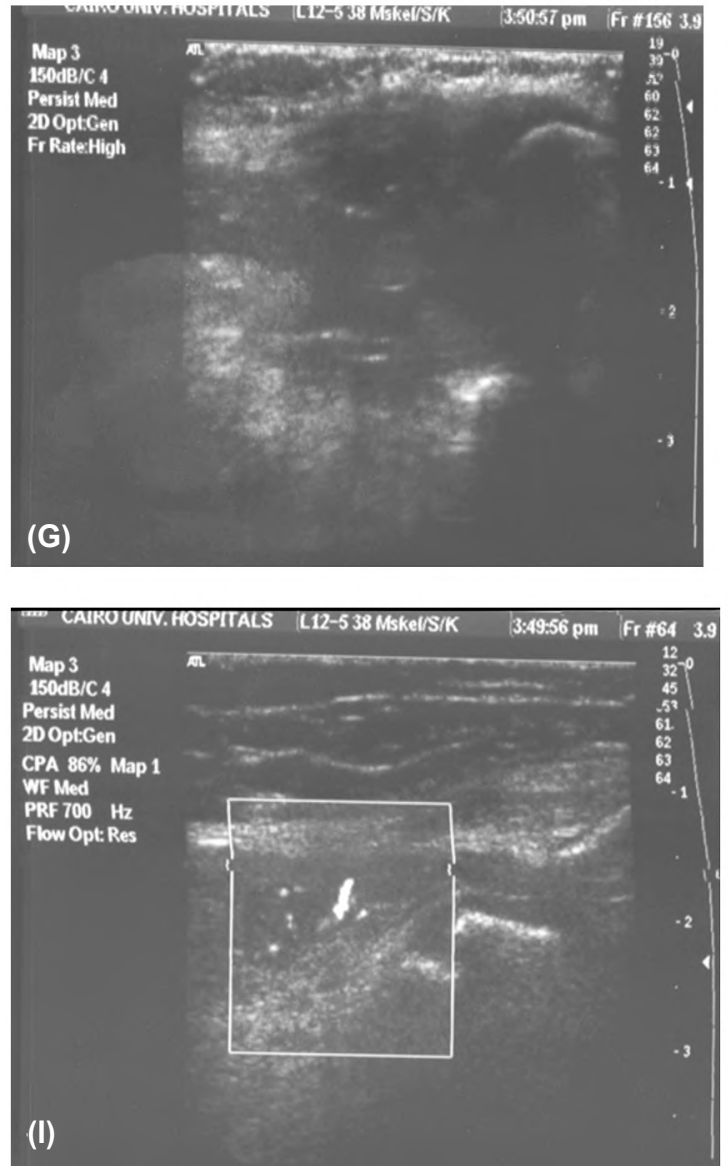

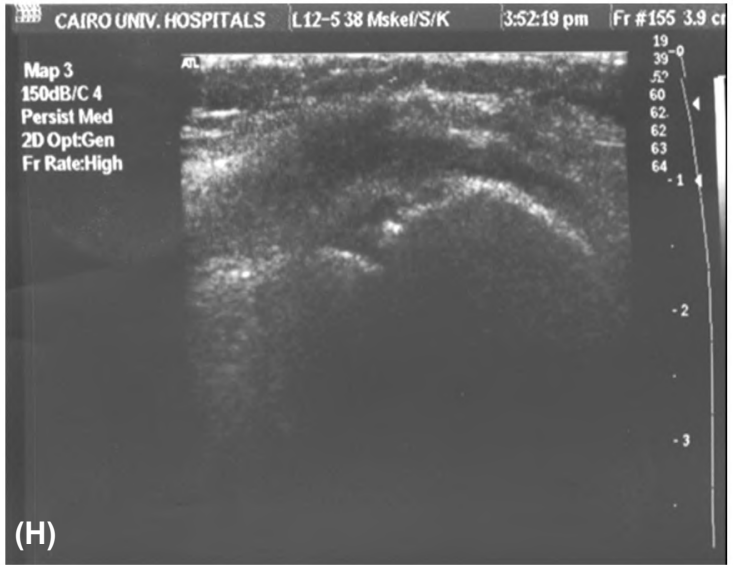

Fig. (13): A female patient, 12 year old, with established diagnosis of polyarticular JIA, uncontrolled on methotrexate therapy. She was admitted to Abo El-Rish Pediatric Hospital during an acute attack. She had bilateral knee joint affection with the right joint being more symptomatic. Sagittal T1 (A) $\&$ T2 WI (B) of the left knee joint showing effusion which appears as high signal intensity on T2 surrounded by thickened synovium in the suprapatellar bursa. There is also bone erosion affecting the articular surface of the upper tibia. Sagittal and Coronal TI SPIR images pre (C,D) and post contrast adminstration (E,F): They show synovial thickening and enhancement. Grey scale ultrasound of the right knee joint showing the effusion $(\mathrm{G})$ \& increased synovial thickening $(\mathrm{H})$. There is also bone erosion that appears as interruption of the hyperechoic bony cortex $(\mathrm{H})$. Power Doppler ultrasound showing increased vascularity of the thickened synovium (I). 
Table (9): Comparison between US and MRI regarding accuracy.

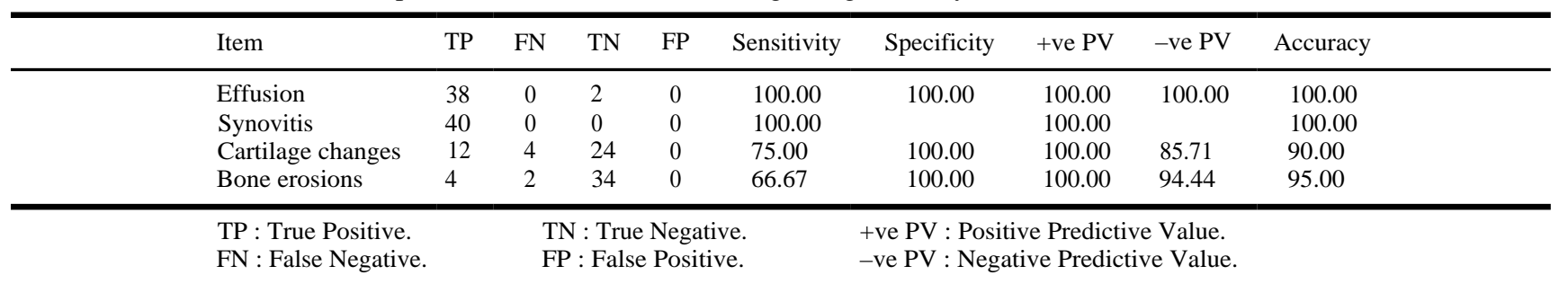

\section{Statistical analysis:}

Data were statistically described in terms of mean \pm standard deviation $( \pm S D)$, and range, or frequencies (number of cases) and percentages when appropriate. Agreement between ultrasound and MRI results was done using McNemar test and kappa statistic. Accuracy of ultrasound markers was represented using the terms sensitivity, specificity, +ve predictive value, -ve predictive value, and overall accuracy. $p$-values less than 0.05 was considered statistically significant. All statistical calculations were done using computer programs SPSS (Statistical Package for the Social Science; SPSS Inc., Chicago, IL, USA) version 15 for Microsoft Windows.

\section{Discussion}

Juvenile Idiopathic Arthritis (JIA) is the most common cause of chronic joint inflammation in childhood. It is an autoimmune disorder with the knee joint most frequently affected. With the increasing availability and use of disease-modifying antirheumatic drugs, demonstration of early joint damage has become important $[\mathbf{3 , 4 , 1 1}]$.

Imaging of Juvenile Idiopathic Arthritis (JIA) is very important in clinical practice. Conventional radiographs are initially used for evaluation and assessment of the disease progression but they are of limited use in early arthritis because they may not show an inflamed synovium, cartilage destruction, and early bone erosions. In addition, since early changes are nonosseous in nature, Ultrasound (US) and MR imaging are superior to conventional radiography and Computed Tomography (CT) for early disease detection $[\mathbf{3 , 1 1 , 1 2 ]}$.

Ultrasound has an important role in narrowing the differential diagnosis, in detecting subclinical disease and diagnosing disease activity. It can detect synovitis, intra-articular effusion, and cartilage thinning or bony erosions. It is cheaper, portable, easy to combine with clinical assessment (interactivity) and non-invasive when compared to other imaging modalities. Sedation is not required allowing follow-up examinations and assessment of multiple joints in the same session
$[3,13,14]$. However, US is unable to examine bone marrow or to reliably detect central erosive changes given the low penetration of the ultrasound beam to the central aspect of the joint with high-frequency transducers $[\mathbf{3 , 1 2 , 1 5 ]}$

MRI is a better imaging modality for the assessment of inflammatory and destructive changes in JIA when compared to conventional radiography, ultrasonography and physical examination. It allows the detection of bone marrow edema, which is considered the precursor for the development of erosions in early arthritis as well as a marker of active inflammation. Also, synovial proliferation, joint effusion, pannus formation, and erosion of cartilage and bone can be detected directly by MRI. Therefore, the role of MRI holds the potential to become an important outcome measure for assessing the knee joint in children with JIA $[3,6]$

This study shows the ability of ultrasound to detect the early changes of JIA namely joint effusion, synovitis, articular cartilage affection and bony erosions. The evidence is that almost all the knee joint changes detected by MRI were also detected by ultrasound.

Ultrasound was able to detect joint effusion in all cases as a compressible anechoic area. It was also able to exclude effusion in one of the patients with controlled disease activity on methotrexate therapy.

It was able to detect synovitis as synovial thickening and increased vascularity on power Doppler in all cases which is evident mainly in the suprapatellar recess. The accuracy of US regarding both effusion and synovitis was $100 \%$.

The variation between the results of this study and the results of others as Kakati P. et al., [16] and Magni-Manzoni S. et al., [17] as regarding joint effusion and synovial thickening, in which ultrasound missed some of the cases, may be related to the small sample size of our study.

Ultrasound can identify the normal cartilage as a clear, smooth and homogeneous hypoechoic 
appearance parallel to that of the cortical bone. In JIA, loss of cartilage thickness, loss of clarity, irregularity, and defects on the surface of the medial and lateral condyle and the intercondylar region are described by ultrasound $[3,18]$. In our study ultrasound was able to demonstrate most of the cases. The overall accuracy regarding cartilage changes was $90 \%$.

In this study six of the cases had bone erosions which were detected on MRI. US were able to detect four of these cases. The overall accuracy of US regarding erosions was $95 \%$. This is not consistent with the results of previous studies Malattia C. et al., [19] in which MRI was the best method for the identification of erosions, revealing more than twice as many erosions as radiography and ultrasonography. The better accuracy of MRI in detecting erosive changes was much more evident with shorter disease duration (3 years).

This may explain the difference between our study and Malattia C. et al., [19]. In our study both patients had disease duration more than 5 years which allowed the erosions to be evident on ultrasonography as well.

MRI has the superiority over ultrasound in being able to detect bone marrow edema, which is thought to be the precursor of erosions. However, no cases with bone marrow edema were encountered in our study.

Although ultrasound examination of the knee joint reveals excellent clinical value, there are still some limitations of our study: The sample size is not large enough for powerful conclusion. Furthermore, a healthy control group, which would have strengthened the study, was not available. Lastly, the application of an US scoring was not done; this is because despite the relatively easy applicability of US, until now there has been no specific US knee scoring system. Rather the US knee examination is part of a more global US score covering multiple joints with respect to disease activity [3].

Another promising technique is 3D ultrasound imaging (termed 4D as it has the advantage of being performed in real time). In a matter of seconds, 3D sonographic pictures of a target area can be acquired allowing for an off-line, exciting virtual anatomical tour in longitudinal, transverse and coronal planes and 3D reconstruction, all at the same time. The main clinical indications for 3D US in rheumatology could include early detection of bone erosions [20].

\section{Conclusion:}

Ultrasound has the ability to demonstrate knee joint pathology in early JIA which can help start early treatment or modify already existing one to prevent permanent joint damage. US has several advantages over other imaging methods, including noninvasiveness, rapidity of performance, relatively low cost, ability to scan multiple joints at one time, repeatability, safety, and high patient acceptability.

At this point in time, however, it is not possible to determine that ultrasound is superior to MRI, especially regarding bone erosions and the fact that it is operator dependent and needs experience.

\section{Summary:}

JIA is the most common chronic inflammatory arthropathy in childhood. It is characterized by arthritis that persists for a minimum of 6 consecutive weeks in one or more joints, commencing before the age of 16 years.

Ultrasound has the ability to visualize joint pathology, assessing disease activity and response to therapy. It also has the following advantages being: Noninvasive, relatively low cost, lack of ionizing radiation, ability to visualize both inflammatory and destructive disease manifestations, easy repeatability, possibility of examining several joint regions at one session, potential for guiding interventions.

The aim of this study was to demonstrate the role of US in the evaluation of knee joint affection in patients with juvenile idiopathic arthritis, especially in early cases, using MRI for comparison.

Our study included 40 patients with the diagnosis of JIA of the knee joints. Ultrasound was able to detect almost all joint pathology.

In conclusion ultrasound holds great promise in evaluation of knee joint in JIA. However, larger scale studies are needed to establish its role in being an integral imaging technique superior to MRI.

\section{References}

1- SUDOL-SZOPINSKA I., MATUSZEWSKA G., GIETKA P., PLAZA M. and WALENTOWSKA-JANOWICZ M.: Imaging of juvenile idiopathic arthritis. Part I: Clinical classifications and radiographs. J. Ultrason., 16 (66): 22536, 2016.

2- BASRA H. and HUMPHRIES P.: Juvenile idiopathic arthritis: What is the utility of ultrasound? Br. J. Radiol., 90 (1073): 20160920, 2017. 
3- HEMKE R., TZARIBACHEV N., BARENDREGT A., BERG J., DORIA A. and MAAS M.: Imaging of the knee in juvenile idiopathic arthritis. Pediatr. Radiol., 48 (6): 818-27, 2018.

4- GULIK E., WELSINK-KARSSIES M., BERG J., SCHONENBERG-MEINEMA D., DOLMAN K., BARENDREGT A., NUSMAN C., MAAS M., KUIJPERS T. and HEMKE R.: Juvenile idiopathic arthritis: Magnetic resonance imaging of the clinically unaffected knee. Pediatr. Radiol., 48 (3): 333-40, 2018.

5- COLEBATCH-BOURN A.N., EDWARDS C.J., COLLADO P., et al.: EULAR-PReS points to consider for the use of imaging in the diagnosis and management of juvenile idiopathic arthritis in clinical practice. Ann. Rheum. Dis., 74: 1946-57, 2015.

6- NARVÁEZ J.A., NARVÁEZ J., LAMA E. and ALBERT M.: MR imaging of early rheumatoid arthritis. RadioGraphics, 30: 143-65, 2010.

7- SPÂRCHEZ M., FODOR D. and MIU N.: The role of Power Doppler ultrasonography in comparison with biological markers in the evaluation of disease activity in Juvenile Idiopathic Arthritis. Medical Ultrasonography, 12 (2): 97-103, 2010

8- The European Skeletal Society Ultrasound Committee. Musculoskeletal ultrasound technical guidelines. V. Knee. (online) Vienna, European Society of Musculoskeletal Radiology, 2007.

9- DESCAMPS M., LIM A. and MITCHELL A.: Ultrasound Examination of the Knee: An Illustrated Guide, 2008.

10- ENTREKIN R.R., PORTER B.A., SILLESEN H.H., WOND A.D., COOPERBERG P.L. and FIX C.H.: Realtime spatial compound imaging: Application to breast, vascular, and musculoskeletal ultrasound. Semin. Ultrasound CT MR, 22 (1): 50-64, 2001.

11-GYLYS-MORIN, GRAHAM T., BLEBEA J., DARDZINSKI B., LAOR T., JOHNSON N., OESTREICH A. and PASSO M.: Early Juvenile RheumatoArthritis: Knee MR Imaging, 2001.

12- SOMMER O.J., KLADOSEK A., WEILER V., et al.: Rheumatoid arthritis: A practical guide to state-of-the-art imaging, image interpretation, and clinical implications. RadioGraphics, 25 (2): 381-98, 2005.

13- MAGNI-MANZONI S., COLLADO P., JOUSSE-JOULIN S., et al.: Current state of musculoskeletal ultrasound in paediatric rheumatology: Results of an international survey. Rheumatology, 53: 491-6, 2014.

14- TOK F., DEMIRKAYA E. and OZÇAKAR L.: Musculoskeletal Ultrasound in Pediatric Rheumatology. Pediatr. Rheumatol. Online J., 9: 25, 2011.

15- BABYN P. and DORIA A.: Radiologic Investigation of Rheumatic Diseases. Pediatr. Clin. North Am., 52 (2): 373-411, 2005.

16- KAKATI P., SODHI K.S., SANDHU M.S., SINGH S., KATARIYA S. and KHANDELWAL N.: Clinical and Ultrasound Assessment of the knee in children with Juvenile Rheumatoid Arthritis. The Indian Journal of Pediatrics, 74: 831-6, 2007.

17- MAGNI-MANZONI S., EPIS O., RAVELLI A., KLERSY C., VISCONTI C., LANNI S., MURATORE V., SCIRE C.A., ROSSI S. and MONTECUCCO C.: Comparison of Clinical Versus Ultrasound-Determined Synovitis in Juvenile Idiopathic Arthritis. American College of Rheumatology, 61 (11): 1497-504, 2009.

18- YUCESOY C., GENC G., BAL A., KEYIK B., OZTURK E., TUZUN M., CAKCI A. and HEKIMOGLU B.: Ultrasonographic Assessment of Knee in Patients with Rheumatoid Arthritis: Is it an Effective Imaging Method for Initial Evaluation? Turk. J. Rheumatol., 26 (2): 120-6, 2011.

19- MALATTIA C., DAMASIO M.B., MAGNAGUAGNO F., PISTORIO A., VALLA M., MARTINOLI C., VIOLA S., BUONCOMPAGNI A., LOY A., RAVELLI A., TOMA P. and MARTINI A.: Magnetic Resonance Imaging, Ultrasonography, and Conventional Radiography in the Assessment of Bone Erosions in Juvenile Idiopathic Arthritis. Arthritis Rheum., 59 (12): 1764-72, 2008.

20- KANE D., BALINT P., STURROCK R. and GRASSI W.: Musculoskeletal ultrasound-a state of the art reviews in rheumatology. Part 1: Current controversies and issues in the development of musculoskeletal ultrasound in rheumatology, Rheumatology, 43: 823-8, 2004. 


\section{دور الرنين المغناطيسى والموجات فوق الصوتية

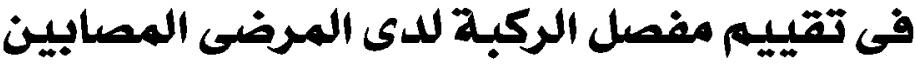 بإلتهاب المفصل مجهول السبب ليب الهرضي}

إلتهاب المفاصل مجهولة السبب يعد من أكثر الآمراض الموماتيزمية شيوعاً فى الآطفال ويتميز بمدة إلتهاب لا تقل عن 7 آسابيع متتالية

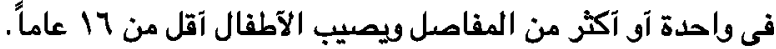

الموجات فوق الصوتية لديها القدرة على تصوير الخلل فى المفاصل وتقييم نشاط المرض وإستجابته للعلاج. كما آن لديها المزايا التالية:

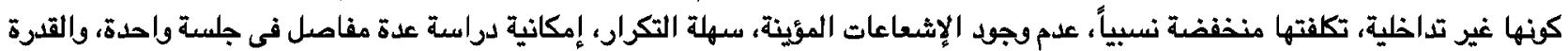
على توجيه التداخلات.

الهدف من هذه الدراسة هو تقييم دو الموجات فوق الصوتية في تقييم إلتهاب مفصل الركبة في الآطفال الذين يعانون من إلتهاب المفاصل مجهولة السبب وخاصة فى الحالات المبكرة، وذلك بإستخدام التصوير بالرنين المغناطيسى للمقارئة.

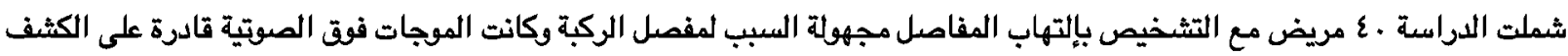
عن جميع مظاهر المرض بالمفصل.

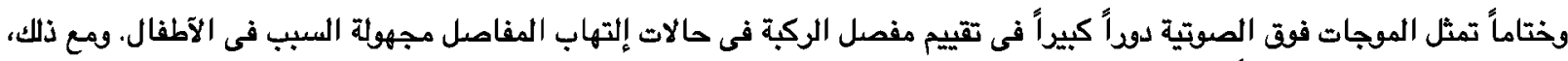

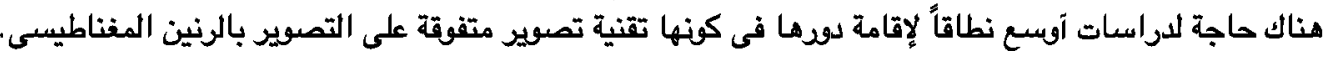

